\title{
LA ENSEÑANZA DEL DERECHO DE LA SEGURIDAD SOCIAL EN MÉXICO Y LATINOAMÉRICA. UN MEA CULPA OBLIGADO
}

\author{
DR. ÁNGEl GUILlermo Ruiz MORENO* \\ Universidad de Guadalajara
}

Uno de los problemas fundamentales que cualquier profesor dedicado afronta cuando se propone comenzar a impartir un curso de Derecho de la Seguridad Social, es la elección de la manera en como hará el abordaje de esta disciplina tan compleja, abigarrada y sumamente evolutiva. ¿Por dónde empezar siendo un tema tan amplio y siempre tan breve el espacio de tiempo disponible? ¿Cómo interesar al educando en un tema que suele ser árido cuando se entra al tema de los requisitos de acceso a las prestaciones? ¿Cómo explicarle a un joven rebosante de vida e ilusiones que cualquier día - por simples contingencias de vida- puede enfermar, accidentarse, llegar a viejo o morir?

Vistas las dificultades que eso entraña, en no pocas ocasiones, porque sin experiencia previa algunos docentes pretenden enseñar una materia que no dominan a cabalidad o cuya trascendencia no terminan de entender, se opta casi siempre por "la vía del menor esfuerzo": los docentes se decantan por hacer a un lado las cuestiones doctrinarias, históricas, teóricas y teleológicas -esto es, que hagan entender al educando la enorme importancia y trascendencia de este magnífico esquema protector, y que contra lo que se cree no son superfluas, pues debieran servir de cimiento firme al difícil proceso enseñanza/aprendizaje de esta disciplina-, eligiendo tratar en clase tan solo cuestiones prácticas y generales, previstas en norma legal, que tienen que ver con el quehacer cotidiano del abogado postulante, y que por su practicidad suelen interesar mayormente al alumno.

Respecto de ello, como docente e investigador dedicado desde hace más de dos décadas a la elaboración desde planes de estudio a libros especializados en la materia, así como a la enseñanza en los niveles de licenciatura y posgrados de esta materia, a mi juicio ese es el mayor error que se comete cuando se imparte el Derecho de la Seguridad Social en las facultades de Derecho de nuestra América morena: querer enseñar la ciencia jurídica con base solo a la norma legal, como si la ley fuese la única expresión del Derecho y no una de sus manifestaciones -siendo esta acaso la más visible, pero definitivamente no la única-. Se enseña pues "con la ley en la mano", y a lo demás se le resta importancia.

Empero, las clases teóricas e históricas no necesariamente deben ser aburridas o áridas, como prejuiciosamente se supone; todo depende de la manera en como el profesor exponga el tema y provoque la participación de los alumnos en la exposición del temario -así como la pertinencia de este-. Este punto es clave, pues se refiere al cómo enseñamos. ¿Acaso alguna vez nos hemos puesto a pensar que de nosotros depende en gran medida si el educando ama, odia o se vuelve indiferente hacia una disciplina jurídica? ¿Quién de nosotros se

\footnotetext{
Presidente Internacional de la Asociación Iberoamericana de Juristas del Derecho del Trabajo y la Seguridad Social "Dr. Guillermo Cabanellas" (AIJDTSSGC.) Autor e investigador nacional de México y de la Universidad de Guadalajara. Contacto: agruizmoreno@aijdtssgc.org
} 
ha cuestionado con absoluta sinceridad qué tipo de profesor es? ¿De verdad alguna vez nos hemos detenido en preguntárnoslo y en respondérnoslo con toda objetividad?

Sin duda, lo que más debiera importar en el ejercicio docente de la ciencia del Derecho es que el educando entienda los porqués de las cosas, esto es: las razones de ser y existir de los entes, las figuras e instituciones jurídicas -en el caso que ahora nos ocupa, específicamente del Derecho de la Seguridad Social-. Porque si el alumno no capta las razones, los porqués, hubo necesidad de verbigracia crearse una especialidad que nace a la vida jurídica al insertarse la seguridad social en el Derecho para volverlo obligatorio -y de paso hacer de él un servicio público exigible al Estado por el particular gobernado-, entonces jamás será capaz de entender las razones de la existencia y exigibilidad de este manto protector, y en consecuencia, pasivamente pensará que es un don gracioso del Estado y acaso hasta lo confundirá con la asistencia social -que no es exigible-, o bien con algún otro esquema de protección social existente.

Aunque suene fuerte decirlo ahora, este asunto de las confusiones conceptuales, nunca suficientemente discutido al seno de la academia en las universidades, es ya hoy en día un grave problema doctrinario en México y en Latinoamérica entera, que ha ocasionado multitud de males, más por simple ignorancia que intencionadamente.

De manera pues que limitarse exclusivamente a enseñar el qué, el cómo, el cuándo o el cuánto de la norma legal, no es suficiente, puesto que no estamos formando a simples "técnicos" del Derecho, sino, por el contrario, a verdaderos cientificos que deben entender los porqués de los fenómenos jurídicos en aras de poder dominar la ciencia respecto de la cual pronto tendrán licencia del Estado para cultivarla y ejercerla.

Aquí subyace el quid del problema en comentario, ya que quienes ejercemos la docencia y a la vez tenemos la elevada responsabilidad de formar a las futuras generaciones de abogados o licenciados en Derecho, por las prisas del mundo de hoy y debido en mucho a la falta de hábitos hacia la lectura o la investigación científica, por la simple comodidad de profesores y alumnos decidimos acotar prejuiciosamente la comprensión del Derecho de la Seguridad Social al marco legal vigente, haciendo un peligroso 'reduccionismo' de lo medular, lo que nada bueno nos augura como sociedad en un futuro mediato.

\section{LA NECESIDAD DE ENSEÑAR EL DERECHO COMO CIENCIA}

Pareciera una obviedad decirlo, pero no lo es tanto: para empezar a resolver la problemática planteada de inicio será necesario comenzar primero por educarnos nosotros mismos, los propios docentes, entendiendo que "el eje" que atraviesa la actual problemática de la seguridad social contemporánea y nuestras sociedades es la educación. Esa es la palabra clave, la llave que nos abrirá la puerta de un futuro mejor.

Sí, hay que educarnos primero los educadores, para poder formar luego a nuestros educandos -que serán algún día los legisladores, gobernantes, jueces, juristas y profesores del futuro-; para eso, en este mundo global que habitamos y en plena era de las comunicaciones, más que informarles habrá que hacer énfasis en formarles, enseñándoles a manejar, procesar y comprender la abundante cuanto dispersa y no siempre confiable información disponible. 
Para ello se requiere actitud -más que aptitud-, y sobre todo un indeclinable compromiso para con las generaciones futuras, y así como para con la universidad que nos permite ejercer este bellísimo apostolado. Siempre teniendo en cuenta que todo lo cientifico es flexible, pues aqui no hay dogmas ni verdades absolutas; por lo tanto, la ciencia está siempre en la búsqueda de la mejor explicación posible, rompiendo paradigmas y descartando mitos, pero sobre todo, cuando se equivoca lo reconoce y sigue buscando para corregir errores cometidos. Para ello un verdadero científico se cuestiona en todo momento, pues esa búsqueda de la verdad científica debe ser permanente y no aislada u ocasional.

De manera pues que la clave del proceso de la enseñanza/aprendizaje del Derecho de la Seguridad Social, será la abierta discusión de ideas, su refutación y la conciliación final que se haga, a fin de que cada uno obtenga sus propias conclusiones, si bien siempre arribándose grupalmente a conclusiones generales válidas para todos. Así, discusión, refutación y conciliación de ideas es la clave de la enseñanza efectiva.

En este punto no olvidemos como académicos que la idea central consiste en cultivar para cautivar alumnos y detectar lo buenos discípulos, haciendo énfasis en las cuestiones fundamentales que a ellos y a los suyos debiera de preocuparles. Un buen método consiste en formular preguntas inquietantes, a cuya respuesta se aboquen grupalmente en una especie de "lluvia de ideas", efectuándose la reflexión serena de cada una de ellas para hacer el natural proceso de descarte y reconfirmación.

A manera de ejemplo, al grupo habría qué plantearles cuestiones tales como:

a) Que la seguridad social es una mera aspiración de todos desde que tomamos conciencia de que los seres humanos somos radicalmente inseguros en este mundo riesgoso en que habitamos.

b) Que dependemos de que el Estado sea efectivamente el garante primario y final de todo sistema de seguridad social para alcanzar un mínimo de protección para una vida digna, justa y apacible. Aquí habrá entonces que tener valor y atrevernos a decirles a los alumnos que si el Estado no puede garantizarlo, entonces nadie podrá hacerlo.

c) Habrá que demostrarles las razones básicas por las cuales solo podrá alcanzarse dicho anhelo -el que por cierto da cuenta de la lucha de la humanidad al través de los siglos- mediante la solidaridad social, razón de ser y fuerza motriz de la seguridad social, sin la cual no existiría, pues el problema es de todos, sociedad y gobierno.

d) Tendremos que convencerlos de que la verdadera justicia no es darle a todos lo mismo, sino darle a cada quien lo que necesita, siendo precisamente la búsqueda de la nivelación de las desigualdades naturales uno de los puntos en los que se explica la seguridad social.

e) Deberemos detenernos a explicarles que la seguridad social es un derecho humano irrenunciable, inalienable e imprescriptible, consagrado como tal en la "Declaración Universal de Derechos Humanos" de la ONU, en sus artículos 22 y 25, para que comprendan sus alcances ${ }^{1}$.

\footnotetext{
1 "Declaración Universal de Derechos Humanos", texto aprobado por la Asamblea General de la Organización de las Naciones Unidas (ONU), el 10 de diciembre de 1948:

"Artículo 22. Toda persona como miembro de la sociedad, tiene derecho a la seguridad social y a obtener, mediante el esfuerzo
} 
f) Habrá que explicar que la seguridad social es un servicio público originariamente a cargo del Estado, la cual no lleva imbíbitos afanes de lucro; por lo tanto, que la misma no es susceptible de ser "privatizada" para beneficios de unos cuantos grupos financieros poderosos, quienes lucran con ella en diversas partes del continente, con una actitud abiertamente permisiva del propio Estado.

g) Que la seguridad social se ha "deslaboralizado" y que hoy día, en vez de seguir al Derecho del Trabajo como antes, le sirve de guía; que entiendan que debido al sensible decremento del trabajo formal, no debe seguir atado el financiamiento de los esquemas de seguridad social contemporáneos a él, por recomendación expresa de la propia OIT.

h) Que es del todo falsa la tesis economicista de que la "seguridad social del siglo XXI es ya infinanciable" (sic), puesto que todo estriba en saber jerarquizar prioridades sociales, empatando y armonizando para ello adecuada e inteligentemente los sustratos político, económico y social del tema de la seguridad social básica con soporte estatal.

i) Que la seguridad social es uno de los esquemas estatales de protección social, pero que no es el único; y además, que es diametralmente distinta -aunque complementaria- a la asistencia social y a la previsión social, esquemas con las cuales suele confundirse.

j) Que por la grandeza de los objetivos que persigue, la seguridad social obligatoria nacional se contempla normativamente en legislaciones taxativas, de orden público e interés social.

k) Que contrario a lo que comúnmente se piensa de manera prejuiciosa, su aplicación es de estricto derecho -a diferencia de lo que sucede con el Derecho Laboral, en donde opera el principio jurídico in dubio por operario-, pues su interpretación no admite suplencias en las deficiencias de que adolezca la queja del asegurado, lo cual no le quita per se su aspecto tuitivo y protector.

1) Que no hay una sola manera de brindar en el mundo el servicio público de la seguridad social, pues depende el mismo del tipo de sistema político y/o económico nacional, así como la manera de entender e instrumentar cada esquema protector de los países del área geográfica.

En fin, el listado de lo que podríamos didácticamente llamar "temas clave", esos que muevan a pensar al alumno y le obligan a razonar para entender a cabalidad el punto medular de las cosas - tan a menudo soslayado e ignorado-, daría como para una obra completa; empero, con dicho elenco temático planteado es más que suficiente para capturar la atención del alumno y de paso demostrar nuestra tesis acerca de la constante evolución de la seguridad social, al tratarse de una disciplina que no está ya hecha, sino que se hace, renueva y transforma día a día.

nacional y la cooperación internacional, habida cuenta de la organización y los recursos de cada Estado, la satisfacción de los derechos económicos, sociales y culturales, indispensables a su dignidad y al libre desarrollo de su personalidad".

"Artículo 25. Todos tenemos derecho a un nivel de vida adecuado, que asegure a nosotros y a nuestra familia, la salud, el bienestar y en especial, la alimentación, el vestido, la vivienda, la asistencia médica y los servicios sociales necesarios. Tenemos, asimismo, derecho a seguro en caso de desempleo, enfermedad, invalidez, viudez, vejez u otros casos de pérdida de nuestros medios de subsistencia por circunstancias ajenas a nuestra voluntad. Tanto la madre que va a tener un hijo, como su hijo, deben recibir cuidado y asistencia. Todos los niños tienen los mismos derechos, esté o no casada la madre”. 
Por lo tanto se equivoca aquel que piense que el Derecho -y sobre todo el Derecho de la Seguridad Social- es inmutable, o que no puede avanzarse más de lo ya hecho, pues siempre habrá algo novedoso qué descubrir en él y qué proponer para mejorarlo, a condición obviamente de que pongamos todos a trabajar nuestro cerebro.

Sin embargo, para aclarar lo antes dicho antes, no perdamos de vista que si provocamos "lluvias de ideas" en clase, habrá también que aclarar ideas-fuerza para que el educando no se confunda, pues el Derecho es una ciencia que se integra por un conjunto de conocimientos metodológicamente obtenidos mediante el uso de razonamientos, los que a su vez han sido sistemáticamente construidos o estructurados, y de los cuales se deducen principios y reglas generales de validez universal.

No obstante ser una ciencia aceptada como tal en todo el planeta, sucede que en pleno siglo XXl el concepto Derecho es todavía un enorme desafío intelectual intentar apresarlo en una simple definición conceptual, debido en gran medida a su constante evolución. Al respecto decía sarcásticamente el propio filósofo alemán Emmanuel Kant, desde finales del siglo XVIII: “...Todavía buscan los juristas una definición de su concepto 'Derecho'...”2. Eso es cierto y la tarea aún prosigue, por lo que resultará mejor explicarlo que intentar definirlo para poderlo entender, pues el concepto "Derecho" es un analogismo práctico mediante el cual se designa tanto a la propia ciencia jurídica, como a las diversas disciplinas que la conforman y hasta las consecuencias de la misma.

Podríase añadir que el concepto Derecho es un adjetivo multívoco, y tan lo es que el Diccionario de la Lengua Española publicado por la Real Academia de la Lengua, asienta 28 distintas acepciones distintas del vocablo, con independencia de las voces que atañen propiamente a las diversas ramas y/o disciplinas del Derecho ${ }^{3}$.

Convendría al punto añadir dos cosas que resultan importantes y trascendentes:

1) Que la ciencia del Derecho, aparte de regular la función del Estado y buscar la coexistencia pacífica de sus habitantes, propende siempre, como un objetivo primordial de su existencia, a la permanente búsqueda de ese valor llamado justicia, pues sin duda el Derecho es el mejor instrumento de la justicia - en la inteligencia de que en el caso del Derecho Social, pues se busca alcanzar la llamada justicia social-; y

2) Que el Derecho, visto y estudiado como una ciencia, es muchísimo más que la simple norma legal, pues aunque la ley tenga como características: ser obligatoria, general, abstracta, coercible, y de observancia forzosa tanto para gobernantes y gobernados, al emanar del poder soberano de una nación, lo cierto es que no deberemos confundirla jamás con la propia ciencia jurídica de la cual la ley forma parte; una parte muy importante si se quiere, la más sobresaliente si se prefiere, pero entendiendo siempre un punto clave: que la ley es una parte del todo jurídico ${ }^{4}$.

\footnotetext{
2 Diccionario Jurídico Mexicano. Instituto de Investigaciones Jurídicas de la UNAM. Tomo II, “d/h”. Decimatercera edición. México: Editorial Porrúa, 1999, p. 935.

3 Diccionario de la Lengua Española. Real Academia Española. Tomo I, "a/g”. Vigésima segunda edición. Madrid: Editorial Espasa Calpe, 2001, pp. 751-752.

4 Diccionario de Derecho Privado. Obra jurídica dirigida por Ignacio de Casso y Romero. Tomo II, "g-z". Segunda reimpresión. Barcelona: Editorial Labor, 1961, p. 2511.
} 
Pese pues a lo incuestionable de todo ello, resulta lamentable que al seno de nuestras propias universidades se siga todavía pensando erróneamente que lo único importante de entender, de considerar o de analizar en clase es la ley, como si todo se resumiese al simple texto legal; o que confundiendo al todo con la parte se le diga al alumno que "la ley es el Derecho" (sic).

Suponemos que quienes así piensan no ponderan que la ley -esto es, la normativa legal expedida por el Poder Legislativo de cada país-, es solo una de las diversas manifestaciones de la propia ciencia del Derecho; porque bien sabemos que la ciencia jurídica es mucho más que la ley, e incluso más todavía que la coloquialmente llamada "Ley de Leyes", la popular manera de nombrar a la Constitución Política de cada nación.

Aunque pretendiese negarse lo anterior, es una realidad incuestionable; al grado de que en las propias facultades de Derecho de México, una gran parte del profesorado que imparten las materias de la seguridad social -así le denominan todavía, en vez de Derecho de la Seguridad Social, lo cual se presta a confusiones conceptuales desde un inicio-, no son abogados, sino contadores públicos o licenciados en administración de empresas u otras profesiones diversas. Pero aclarémoslo para evitar confusiones: ¿cómo la intentan enseñar ellos, sin tener el perfil académico adecuado? ¡Pues con el simple texto legal en la mano! [Verbigracia: "El artículo x dice esto...", y lo leen, y a ello sigue siempre la pregunta clásica: ¿está claro, alguna duda o comentario? Y obvio que no hay nada que decir porque no se enseña a razonar de manera crítica al alumno, y naturalmente que tampoco hay dudas, porque tan solo lo leen, pero no lo interpretan].

Bien sabemos los juristas que una cosa es leer y otra muy distinta entender, comprender y captar el precepto legal, es decir: el sentido regulador de la norma y su espíritu; pero ese tipo de profesores no doctos en el Derecho de la Seguridad Social -en razón de su perfil académico ya que no han sido entrenados para ello, no porque sean tontos-, sencillamente no explican los alcances del precepto en aparente estudio porque es muy probable que ni ellos mismos lo entienden.

¿Y los alumnos? Pues allí están: sentados, completamente aburridos, con la mente en cualquier otro lado, desinteresados de su realidad al ser esclavos de la prisa y la indecisión -dos grandes males de nuestra era-, enfadados con una materia por la que no sienten ninguna atracción porque no son capaces de captar su trascendencia, y lidiando a diario con un profesor que lejos de inspirarles, les ha provocado una abierta aversión a la disciplina.

Al menos el que esto escribe -en un mea culpa obligado-, debe públicamente reconocer que de un grupo de 50 alumnos a nivel licenciatura, acaso termina rescatando al final de curso a alguien que le guste el Derecho de la Seguridad Social para ejercerlo en su vida profesional o en la docencia; aunque a nivel posgrado -cuando ya se ha ejercido la profesión y sobre todo se ha entendido la problemática de la vida real-afortunadamente el porcentaje suele ser mayor.

Reconozcámoslo entonces: intentamos educar en las aulas a los futuros profesionales que adolecen de verdadero sentido crítico-constructivo de su realidad y de su entorno social; jóvenes que no tienen "conciencia de clase ni clase en la conciencia" debido en parte a la manera en como nuestras universidades trasmiten los conocimientos en esta disciplina; seres humanos que no han sido realmente formados, sino, a lo más, informados, los que para col- 
mo piensan que es más confiable la información que brinda Internet que un libro jurídico; individuos que han sido entrenados solo "a leer la ley", a acatarla pero no para entenderla.

En resumen: es una verdad incontrovertible que las facultades de Derecho latinoamericanas mandan a las calles semestre a semestre, año con año, con una gran desventaja formativa (¿deformativa?), a millares de noveles licenciados del Derecho mal instruidos, condenados a pelear en su vida profesional batallas perdidas de antemano. Aquí, dejando de lado algunos otros aspectos, la gran interrogante a responder es desde la óptica académica: ¿qué sucederá si tales alumnos son luego, por azares del destino, profesores de la materia del Derecho de la Seguridad Social en alguna universidad pública o privada? Una cuestión harto inquietante, sin duda.

\section{LA CRISIS DEL DOCENTE DEL DERECHO DE LA SEGURIDAD SOCIAL}

Pues bien, una vez captado todo el entorno y la problemática que subyacen tanto respecto de la notoria escasez de verdaderos expertos del Derecho de la Seguridad Social, añadámosle otros ingredientes al problema, como resulta ser la desinformación que provocan en la ciudadanía las opiniones políticas encontradas, las notas periodísticas carentes de cientificidad y de todo rigor metodológico en sus investigaciones a las cuales la gente les da un margen de credibilidad abrumador, así como juicios interesados en la agria disputa de las corrientes de "izquierdas" y "derechas" en nuestras sociedades, y tendremos un panorama francamente desolador.

Sin duda de esa sentida problemática -junto a otras cuestiones colaterales que también influyen en el tema- se deriva la enorme crisis de docentes de la disciplina del Derecho de la Seguridad Social, de que adolece nuestra América Latina.

En efecto, una verdad como un puño es que la seguridad social y todo lo que le rodea hoy día, es una especie de "mundo mítico" en donde las medias verdades -que terminan siendo mentiras completas- es el pan de cada día, y en donde los rumores surgen intencionadamente, los que de tanto repetirse de repente se vuelven en parte de la realidad.

El popular aforismo: "una mentira repetida mil veces se convierte en verdad", es totalmente cierto, de manera que los enemigos del magnífico esquema protector de la seguridad social contemporánea -quienes han visto en ella y en su eventual desmantelamiento una especie de botín susceptible de ser repartido- han propalado intencionadamente al través de los medios de comunicación masiva las ideas de que: "la seguridad social es un barril sin fondo que se traga enormes recursos públicos", o juicios de valor como que "la seguridad social es cara y mala", o argumentan sin pruebas que "la seguridad social es un gasto inútil del Estado".

De manera que debemos todos los docentes de esta materia tener muy claro que es urgente terminar con los mitos de la seguridad social de una buena vez. Y para poder lograrlo debemos estar bien informados, permanentemente actualizados, amén de ser muy analíticos para observar los hechos con objetividad y sin apasionamientos, teniendo siempre el valor ético de decir lo que opinamos, lo que pensamos, aunque debamos pagar el precio de ir contra corriente de ser necesario. No hay otra alternativa posible.

Así, los profesores no debemos tener miedo a equivocarnos de vez en cuando si ac- 
tuamos de toda buena fe en nuestro ejercicio docente, ni a manifestar nuestras dudas en clase exteriorizando nuestras inquietudes científicas; tampoco debemos temer generarlas en nuestros propios pares, o hasta en nuestros directivos y alumnos, pues los problemas de la seguridad social no son exclusivos de alguna persona o grupo social: son de todos como colectividad organizada. Comencemos siempre por lo básico: nadie sabe todo, ni tampoco lo sabe para siempre.

Pero el temor a ser criticados por nuestros pares y alumnos nos hace dudar, perder la confianza en nosotros mismos y entonces optamos por mantener la boca cerrada, considerando que "quien habla menos se equivoca menos". El que habla prefiere pensar a ese respecto que "quien no habla, Dios no lo oye", y al que se queda callado, que la ciencia lo ignora. Por lo tanto es mil veces preferible preguntar antes de seguir viviendo en la ignorancia.

Precisamente por eso debemos alentar a los alumnos a preguntarnos, pues si no sabemos la respuesta a su inquietud, juntos ellos y nosotros la buscaremos afanosamente hasta encontrarla y así salir de dudas ambos. Les digo textualmente para provocarlos -desde luego con el debido respeto que se merecen como individuos-: "jóvenes, no hay preguntas tontas, sino gente tonta que no pregunta"; y por lo regular, ante dicho comentario logro vencer la timidez, su indecisión, o mejor aún: la indiferencia para con la clase, haciendo que participen activamente y se involucren en ella.

Esa es nuestra ineludible responsabilidad profesional que, siendo sinceros, no hemos sabido, podido o querido cumplir, permitiendo de paso que a los iuslaboralistas, junto a los segurólogos sociales ${ }^{5}$, se nos considere cultores de "una rama menor del Derecho" (sic), como prejuiciosa e injustificadamente consideran a quienes nos dedicamos al Derecho Social.

Por cierto, vale la pena explicar brevemente por qué nuestros ácidos críticos (los civilistas y iusprivativistas en general) nos dicen que somos "cultores de disciplinas menores": porque no evolucionamos a la par de la realidad; porque nos hemos quedado estáticos por simple comodidad en principios y valores jurídicos que si bien eran válidos a mediados del siglo XX, en el XXI ya fueron totalmente rebasados; porque vivimos en eternas indefiniciones doctrinarias y conceptuales, sin atrevernos nunca a asumir posturas ni a tomar partido respecto a su natural evolución. Centrémonos en esto último: las confusiones conceptuales del Derecho Social, al no ser resueltas ni siquiera al seno de las universidades o en foros temáticos especializados que reúnen a académicos expertos, se convierten en la vida real en problemas jurídicos mayúsculos.

Efectivamente, uno de los problemas más sentidos en esta disciplina consiste en que alguna de las llamadas fuentes formales de la ciencia del Derecho -fuentes de las cuales surge o nace el propio Derecho, y de paso le nutren e informan permanentemente-, no son tomadas en cuenta. A manera de ejemplos, la llamada doctrina jurídica (es decir: la teoría u opinión de los tratadistas), o los principios generales del Derecho (que son las ideas fundamentales no escritas,

\footnotetext{
5 Segurólogo social deriva de social security (seguridad social), mediante el cual se conoce y reconoce a quienes se han dedicado por entero al estudio, cultivo e investigación de la Seguridad Social. En el ámbito jurídico, un segurólogo social es un jurista con un perfil distinto al juslaboralista, porque su campo de acción debe abarcar no solo lo propiamente laboral -Derecho del Trabajo o Burocrático-, sino también lo concerniente a figuras jurídicas emanadas de los Derechos Administrativo, Económico, Fiscal y Financiero del Derecho, que ya han cobrado carta de naturalización en el actual Derecho de la Seguridad Social.
} 
pero evidentes, los cuales son inmutables salvo algunos casos verdaderamente excepcionales), o bien la jurisprudencia (esto es, los criterios de interpretación de las normas que elaboran los tribunales judiciales competentes para ello), pese a también formar parte integrante de la llamada ciencia jurídica o Derecho, rara vez en la práctica son debidamente estudiadas, analizadas, ponderadas y mucho menos comprendidas a cabalidad. Para decirlo más claro todavía: un abogado o licenciado en Derecho, para serlo, no estudió "leyes", sino la ciencia del Derecho; y no estudió tampoco "jurisprudencia”, sino la ciencia jurídica globalmente vista y entendida.

Toda esa confusión conceptual es perjudicial para todos, pues mientras vivimos en la academia en la permanente indefinición, la sociedad en general la padecerá; de manera pues que si ni siquiera los profesores nos atrevemos a asumir la responsabilidad inherente a todo maestro que se precie de serlo -esto es: explicar al educando que el Derecho es ante todo una ciencia, y que no necesariamente todo lo legal tiene por el hecho serlo un genuino sustento jurídico en cuanto al fondo del asunto-, menos los alumnos entenderán el punto fino al no comprender los "porqués" de las cosas. Y si no lo entienden es porque no se las decimos, ni se las explicamos.

Siendo muy francos, esas actitudes ausentes de compromiso del binomio profesor/ alumno (claro, ante el silencio cómplice de las propias autoridades universitarias), son la constante en nuestras facultades de Derecho en México, Centro y Sudamérica, así como en el Caribe latino, lo cual ha vuelto el tema jurídico en un verdadero "galimatías", una maraña de temas y normatividad legal o reglamentaria que de suyo somos incapaces de comenzar a desenredar al no contar con las herramientas científicas necesarias para acometer con eficacia tales tareas. Y si ni siquiera podemos hacer un buen diagnóstico y corregir nuestro actuales planes o programas de estudio -junto con el nivel del profesorado-, menos podremos resolver la problemática que padecemos todos como sociedad.

Seamos más sinceros todavía y pongamos de una buena vez el dedo en la llaga -que para eso deben servir estos congresos y eventos académicos de expertos: para reconocer y diagnosticar problemas para luego buscar soluciones-: los abogados hemos fallado a la sociedad en general debido a nuestra pasividad o indiferencia acerca del tema, acaso para evitar ser cuestionados o criticados por nuestras opiniones vertidas. Reconozcamos también que muy rara vez nos atrevemos a poner los puntos sobre las ies, dando por descontado que el resto de la sociedad sabe, entiende o capta las sutiles diferencias terminológicas -a veces simple cuestión de énfasis entre un concepto u otro-, diferencias que no pocas veces somos incapaces de percibir hasta los propios jurisperitos.

Habrá que decir entonces las cosas muy claras, para que no queden dudas ni se dé cabida a interpretaciones interesadas. Por ejemplo, decir que tratándose de asuntos laborales, si bien cualquiera puede hablar acerca del trabajo, visto y entendido este como un fenómeno social al ser un deber y un derecho socialmente útil -máxime que subordinadamente o no, lo cierto es que todo el mundo trabaja, incluyendo aquí a nuestros políticos, legisladores, gobernantes, líderes sindicales, etc.-, solo los abogados podríamos hablar calificadamente acerca del Derecho del Trabajo, en razón de nuestro perfil profesional y como expertos en la ciencia jurídica. Parece lo mismo, pero lejos está de serlo, pues un cosa es el concepto "trabajo" y otra muy diferente "Derecho del Trabajo". Por eso hay qué decirlo claro y fuerte, sin temores, al fin que si nos equivocamos tendríamos siempre la oportunidad de rectificar. 
Empero, pareciera que nadie es capaz de decirles de frente a nuestros políticos o a los periodistas -quienes salvo que sean juristas carecen de los conocimientos y de los métodos de interpretación de las normas e instituciones laborales- que se abstengan de hacer juicios a priori acerca del Derecho del Trabajo o del de la Seguridad Social, pues emiten sus juicios como si en realidad fuesen expertos juristas.

De suyo nadie podría hacerlo mejor que nosotros, los académicos e investigadores nacionales, aunque en la práctica guardemos a veces un silencio cómplice que es vergonzante para quienes hemos tenido la fortuna de haber sido instruidos, dándole así la espalda a nuestra función natural de educadores - una responsabilidad que, valdría la pena recordarlo siempre, no se agota en el salón de clases-. Acaso por eso mismo no se nos valora a los profesores, a los académicos, a los investigadores, ni a las universidades de cuya plantilla docente forman parte: porque guardamos siempre conveniente silencio cuando deberíamos exigir ser tomados en cuenta. Sí, "lavarse las manos" es un buen método de volverse cómplices de los hechos, pues sin intentar mezclar aquí a la religión, por lo conocido del hecho nos resulta útil el ejemplo para ilustrar nuestro comentario: un tal Poncio Pilatos nos dio muestra palpable de ello.

Después de todo, ¿quién de nosotros les va a explicar a la clase política, a los periodistas o comunicadores -nunca son lo mismo, que conste-, o a la sociedad en su conjunto, que no es lo mismo la asistencia social o la previsión social, que la seguridad social? Claro está que todas ellas son formas distintas de un esquema global de la protección social nacional, aunque cada una tiene sus propias características; sutiles diferencias entre ellas, si se quiere, pero diferencias que les distinguen al fin y al cabo.

Y tras de ello obligarnos a nosotros mismos, los juristas y académicos, a responder estas nuevas cuestiones que nos plantea la ominosa realidad del siglo XXI:

a) ¿Quién de nosotros entiende acerca de la nueva conceptualización de soberanía nacional, o de las normas supranacionales?

b) ¿Quién viene a explicar a sus pares o a sus alumnos lo que es la subordinación en las nuevas relaciones laborales del siglo XXI?

c) ¿Quién es capaz de desentrañar el enigma jurídico existente entre los conceptos derechos humanos y derechos sociales, que obviamente no son ni significan lo mismo?

d) Quiénes de los presentes sigue pensando aún que el Derecho del Trabajo y el de la Seguridad Social continúan ineluctablemente unidos, ligados entre sí cual siameses imposibles de separar?

e) ¿Quiénes piensan todavía que ambas disciplinas jurídicas son en realidad verdaderos Derechos Sociales exigibles al Estado?

Porque las diferencias conceptuales prealudidas pueden ser tan sutiles como se quiera, pero lo cierto es que existen y es nuestro deber puntualizarlas científicamente, siempre con estricto rigor académico para no confundirnos jamás en una ciencia social que a todos debiera interesar no hubiesen jamás errores, lagunas u obscuridades $-y$ por el contrario: que fuese siempre clara, nítida, prístina y transparente como el agua limpia, que algunos sin querer y otros interesadamente terminan por enturbiar-. Porque si los llamados "puntos 
finos" de la ciencia del Derecho no los sabe ni entiende un jurista, o finge no hacerlo interesadamente, entonces el problema se amplifica de manera tal que llega a afectar no solo a la sociedad en general, sino a la propia ciencia jurídica al propiciar errores fatales.

En ese mismo hilo de ideas: siendo el Derecho la ciencia del "deber ser", debería entonces ser preocupación fundamental del Estado educar acerca del tema para que nada ni nadie -mucho menos nuestros gobernantes, legisladores o administradores de justicia- se pongan por encima del Derecho; que por lo tanto, como debe ser en un "Estado de Derecho", todos los habitantes de un país, en cualquier nivel o posición en que se encuentren, se sujeten y se sometan a él, sublimando siempre sus intereses personales al interés general nacional.

Sin embargo, por desgracia a diario hay pruebas irrefutables de que las cosas no son exactamente así como las planteamos, aunque los numerosos ejemplos que lo confirman sea imposible plasmarlos aquí por simples razones de tiempo y pertinencia.

Por lo tanto, es necesario comenzar a cuestionarnos y responder todos con absoluta sinceridad, a fin de terminar de una buena vez con esa "torre de Babel académica" en donde pareciera que hablamos de lo mismo, pero cada uno entiende las cosas de manera distinta, al menos las preguntas clave, a saber:

a) ¿Quién de nosotros asume con valentía que el mundo jurídico de hoy es muy distinto del que nos enseñaron en las aulas nuestros queridos profesores hace 2, 3 ó 4 décadas?

b) ¿Quién sigue en pleno siglo XXI, la era de la información, enseñando el Derecho con "la ley en la mano"?

c ¿Quién de mis amigos académicos aquí reunidos reconoce abierta y públicamente que es verdad aquella provocadora idea de que la realidad es más sabia que el Derecho?

Acaso es que de antemano sabemos ya todas las respuestas. El problema estriba más bien en que no nos atrevemos a formularnos las preguntas correctas y pertinentes.

\section{LA ENSEÑANZA DEL DERECHO DE LA SEGURIDAD SOCIAL EN MÉXICO}

Por último, interesado permanente en todo lo que atañe a las cuestiones de la seguridad social contemporánea, sus vertiginosos cambios y su ominoso futuro, advertimos que en realidad son muy pocos los juristas que con dedicación cultivan esta singular disciplina jurídica, fundamentalmente porque con gran cortedad de miras se le sigue viendo como un simple apéndice del Derecho del Trabajo, cuando para ser sinceros, en el mundo entero la seguridad social se ha convertido en una de las estrategias políticas, económicas y fiscales más trascendentes de los Estados contemporáneos. Todavía más: estamos más cerca de un Derecho Contributivo o Fiscal de la Seguridad Social, que de un asunto propiamente laboral.

Pero además, hay un hecho inobjetable e incuestionable, el cual debiera movernos por igual a todos los juslaboralistas y segurólogos sociales a la reflexión académica serena y comprometida: la palpable deslaboralización de la seguridad social.

En efecto, no obstante los dramáticos cambios sufridos en poco más de un siglo, tercamente nos empecinamos en seguir "atando" a la seguridad social del siglo XXI a lo que fue 
cuando nació -allá por la penúltima década del siglo XIX, con la ya obsoleta idea bismarckiana del Seguro Social exclusivo para trabajadores subordinados-, creyendo que solo tiene que ver este magnífico esquema protector con el trabajo formal y regulado; porque al decaer el empleo en épocas de recesión económica y cuando nuevas formas laborales invaden el mundo que nosotros los jurisperitos conocíamos, cuando el desempleo vaga como fantasma por todos los puntos cardinales del planeta, tratar de atar al servicio público de la seguridad social al trabajo formal socava de raíz el financiamiento de este servicio público, que es un derecho humano y social inalienable, irrenunciable e imprescriptible, a la par que es también una responsabilidad ineludible del Estado visto como el garante primario y final de este magnífico sistema protector.

No es fácil para los juslaboralistas "puros y duros" hablar acerca de la indudable deslaboralización que ha sufrido la seguridad social contemporánea, e incluso es frecuente que se le continúe ligando con el Derecho del Trabajo, al seguir considerando sin razón que la seguridad social es apenas un simple apéndice de aquel. Empero, ya Néstor de Buen Lozano, uno de los más prestigiados juslaboralistas de la actualidad -quien ha incursionado con éxito en la seguridad social, y hasta obra escrita tiene en esta materia-, señala con rigor académico y singular acierto, una reflexión aleccionadora:

"Una deformación antigua de los conceptos ha asociado históricamente al Derecho del Trabajo con el Derecho de la Seguridad Social. Los planes de estudio de las universidades suelen colocarlos juntos, a veces en la compañía comprometedora del Derecho Burocrático, en una especie de síntesis de lo más importante del Derecho Social. Por el mismo motivo se ha considerado, por supuesto que sin razón, que ser laboralista lleva en si mismo el germen de la especialidad de la seguridad social. Nada más falso" 6 .

Ello explica entonces, de alguna manera, la ausencia de verdaderos tratadistas y expertos estudiosos del Derecho de la Seguridad Social (léase: de segurólogos sociales) ${ }^{7}$, pues los abogados hemos abandonado el cultivo de esta hermosa disciplina, y hemos dejado que asuman el liderazgo ideológico los economistas, los matemáticos actuarios, los contadores públicos, y toda la gama de profesiones que se dedican en la vida cotidiana al simple cumplimento de obligaciones contributivas o bien a la creación de estrategias fiscales en la materia de la protección social. Esa es la razón por la que sostenemos que si el Derecho de la Seguridad Social nos abandona, lo hace en simple reciprocidad al abandono en que la hemos mantenido los juristas desde hace décadas.

Prueba de todo ello es, como gran ejemplo, la siempre escasa bibliografía disponible en México, mi patria, muy a pesar de que se supone ejerce un liderazgo nato en América

\footnotetext{
6 De Buen Lozano, Néstor de, Seguridad Social. Editorial Porrúa: México, 1995, p. IX. Por cierto, la cita en comentario es el primer párrafo del capítulo introductorio de dicho libro.

7 Segurólogo Social (véase nota 5) quien se dedica de manera preferente al estudio y cultivo del Derecho de la Seguridad Social, como disciplina autónoma hoy día prácticamente desligada del Derecho del Trabajo. Cabe apuntar que para manejar adecuadamente esta compleja disciplina jurídica, deben tenerse conocimientos múltiples, entre ellos de las siguientes disciplinas básicas del Derecho: Administrativo, Fiscal, Laboral o Burocrático, Económico y Financiero.

Por cierto, la Asociación Internacional de la Seguridad Social (ISSA, por sus siglas en inglés) es el órgano técnico de la propia OIT que se encarga de manera específica de esta temática; su sede se encuentra en Ginebra, Suiza, su página web de Internet es: www.issa.int y su correo electrónico de contacto es: issa@ilo.org
} 
Latina en cuestiones que atañen a los Derechos Sociales desde 1917 -cuando se promulgó la primera Constitución Social del planeta y se creó el ya mítico artículo 123-, pues por cada cien libros, ensayos o artículos publicados en materia del Derecho del Trabajo y demás temas afines al mundo laboral, encontramos acaso uno relativo al Derecho de la Seguridad Social ${ }^{8}$; de manera pues que nos sobran dedos en las manos para contar las obras existentes en esta materia.

Ello se traduce en que el ciudadano común piense y sienta -acaso con razón- que no hay en México una verdadera justicia aplicada en esta disciplina, si ni siquiera existen tribunales jurisdiccionales verdaderamente especializados que brinden a la población el servicio clave de la tutela efectiva de sus derechos. Nada o, en el mejor de los casos, muy poco se hace para revertir esta sentida problemática social.

Y que conste al punto que no proponemos crear estancos o pretendemos parcelar cada disciplina jurídica, sino que estamos convencidos de que se requiere de tribunales especializados, integrados por verdaderos expertos en la administración de justicia en esta delicada materia, profesionales de la ciencia jurídica que lamentablemente no forman nuestras universidades desde el aula, pues en al menos la mitad de las facultades de Derecho de México, en los mapa curriculares de la carrera jurídica no existe la disciplina del Derecho de la Seguridad Social.

¿Cómo defender entonces un derecho que se ignora?, sobre todo en una materia en la cual inciden de manera importante otras disciplinas jurídicas interrelaciones, tales como los Derechos Administrativo, Fiscal, Laboral, Burocrático, Económico, Financiero y Bursátil.

Todo ello, en resumidas cuentas, produce un grave desequilibrio social e impide que la seguridad social cumpla con su función niveladora y redistributiva del ingreso nacional que le corresponde. O dicho de otra forma a manera de colofón: el problema se traduce en una grave injusticia social, la cual lesiona no a individuos, que ya es grave, sino irremediablemente toda la colectividad organizada, que es peor.

\section{PROPUESTAS DE SOLUCIÓN A LA PROBLEMÁTICA PLANTEADA}

1) Debemos comenzar por reconocer que hacen falta buenos profesores en nuestras universidades públicas o privadas, que se dediquen por vocación a la enseñanza del Derecho de la Seguridad Social. Porque es palpable el abandono en que los juristas hemos tenido a la seguridad social, es prioritario y urgente rescatarla del arcón del olvido, antes de que sea demasiado tarde. Este mundo global en que vivimos, en donde imperan las feroces "reglas del mercado", nos impone nuevos retos que debemos afrontar con entereza, responsabilidad y altitud de miras.

De manera pues que las universidades - públicas o privadas, en ello no hay diferencia sustancial- deben tener muy en claro que las problemáticas de la seguridad social que afrontamos no se resolverán como por arte de magia, sino que deben de efectuarse diagnósticos serios y responsables, en la búsqueda de las anheladas propuestas de so-

8 Datos extraídos del "Informe 2005" de la Academia de Derecho de la Seguridad Social, la Previsión y el Trabajo, pionera en su género y la cual me honro en presidir, domiciliada la misma en la ciudad de Guadalajara, México, de un estudio-encuesta entre autores de libros y artículos jurídicos efectuado para medir el impacto e interés académico del Derecho de la Seguridad Social, respecto del Derecho Laboral. 
lución que la clase política, por sí misma, es incapaz de encontrar sin nuestra colaboración. Y esa ingente tarea nos corresponde a los académicos.

2) Nuestros alumnos no son tontos, pues nos "miden" a los profesores desde el momento que nos ponemos frente al grupo, y de inmediato nos toman la medida. Nos podemos engañar nosotros, pero a ellos difícilmente lo haremos, y su juicio será implacable. Los alumnos no son botellas vacías que debemos llenar de conocimientos, sino que son lámparas que encender; cada uno ya trae su propia "luz" -y todas ellas de diferentes intensidades, por cierto-. Eso habrá qué entenderlo en nuestro compromiso ético docente para con la ciencia que cultivamos y especialmente respecto del proceso de la enseñanza en que participamos cotidianamente.

Entonces hay que atrevernos a ser sinceros y ser nosotros mismos. En la elección del perfil adecuado del profesor de Derecho de la Seguridad Social se encuentra la mayor parte del problema (he allí la famoso regla de administración "80/20" de Pareto, quien sostuvo que el $80 \%$ de los problemas se localizan en el 20\% de las causas, de manera que al focalizar estas y combatirlas, aquellos obstáculos tenderán a desaparecer).

Hay qué atrevernos a actuar y correr el riesgo de fallar -aceptando que los humanos somos seres falibles-, pero luego con humildad reconocerlo para reconducir el camino a tiempo; hay que ser congruentes y consistentes, sí, pero nunca "casarnos" con nuestras propias ideas, porque la vida es harto evolutiva y es posible que lo que era válido en una época, ya no lo sea en otra; respetando siempre a los que difieran de nosotros como esperamos que ellos respeten nuestra propia ideología; reconvengamos con inteligencia y con la fuerza de la razón a quienes se creen dueños únicos de la verdad; cimbremos a quienes consideran "hecha" e inmutable a la ciencia jurídica pensando erróneamente que ya lo saben todo; sacudamos a quienes se niegan a reconocer que la realidad es más sabia que el Derecho y que, de no estar atentos, aquella rebasará a este en cualquier momento. Porque después de todo, vivimos en el seno de una Universidad, y ello implica la universalidad de pensamientos e ideas. En la Universidad nadie tiene razón a la fuerza, ni la fuerza de una razón única.

3) Querámoslo o no reconocer, formamos parte de la llamada "generación perdida" de la seguridad social. Tenemos una enorme deuda intergeneracional para con nuestros hijos y las generaciones futuras, que debemos intentar saldar antes de que nos gane la desesperanza, y que los problemas inherentes ahora a la seguridad social se conviertan, al paso de los años, primero en un problema de seguridad pública, y luego en un asunto de seguridad nacional.

Al menos que no se diga que nadie advirtió a tiempo, pues no existe otra alternativa posible para México, para Nicaragua, y de suyo para toda nuestra América morena: sí, hay que hacer especial énfasis en la educación, y principalmente en la educación previsional que tan ausente está en nuestra idiosincrasia. Porque no es solo un problema del Estado, sino que se requiere de la participación de todos nosotros, de una insoslayable responsabilidad individual para que los esquemas de protección social puedan ser materializados. 
Por ello depositamos íntegramente nuestras esperanzas en que trabajemos todos juntos: gobernantes y gobernados, legisladores y jueces, los llamados "actores sociales" en el mundo tripartito de la seguridad social tradicional -y los que en el futuro inmediato llegaran a sumarse-; al igual que hacemos fervientes votos de que lo hagamos quienes nos hallamos inmersos en la vida académica, desde cualequier trinchera en la que sirvamos: ya sea como directivos universitarios, docentes y administrativos, o bien como alumnos o padres de familia, quienes junto con la ciudadanía en general podremos cambiar radicalmente el actual estado de cosas que nada bueno augura para las generaciones futuras y los seres que más amamos e importan en la vida: nuestros hijos y los hijos de ellos.

En ello depositamos íntegramente nuestras ya frágiles esperanzas. 